\title{
On the Construction and Evaluation of Power Supply
}

\section{Enterprise's Strategic Capability}

\author{
Shengming Hou \\ Business Administration School, North China Electric Power University, Beijing 102206, China \\ E-mail: kangwei63@yahoo.cn
}

\begin{abstract}
It is extremely important to make a scientific evaluation on enterprise's strategic capability. Focusing on the power supply enterprise, this paper designs a "five-force" mode composed by strategic capabilities and advances a complete strategic capability evaluation system. In addition, this paper proves the system's feasibility and practicability by case study. To sum up, this paper provides with an effective method for the evaluation of power supply enterprise's strategic capability.
\end{abstract}

Keywords: Strategic capability, Power supply enterprise, Analytic hierarchy process (AHP)

\section{Introduction}

In enterprise management, in order to adapt to changes of environment and allocate resources effectively and obtain better effects, to possess stronger strategic capability is an indispensable factor for the enterprise. The study of enterprise's strategic capability evaluation can help the enterprise evaluate its strengths more exactly and comprehensively. Understand its advantages and disadvantages. Develop the advantages and improve the disadvantages. Enhance the strengths from all aspects instead of one aspect. Finally realize the enterprise's long-term coordinative development and sustain its initiatives in competition in the long run. As a result, the enterprise can obtain better corporate performance. Therefore, the exact evaluation of enterprise's strategic capability serves as the base of management, which provides with a relatively real and reliable basis for managers in making decision.

\section{The connotation of strategic capability}

For an enterprise in its whole development process, as the enterprise can make up relevant enterprise strategy, implement relevant strategic management methods, and guarantee an effective application of enterprise strategy, the enterprise possesses strategic capability. The cultivation and utilization of enterprise's strategic capability are the sufficient conditions for the enterprise creating sustainable competitive advantages and the key ensuring the enterprise's sustainable development (Wensong Zhang, 2005; Xiaoping Xu \& Wei Liu, 2006).

Differing from common industrial enterprises, the power supply enterprise is a special enterprise that aims at transferring, distributing, and selling electricity. Its production and operation have unique characteristics and follow special laws. Based on the enterprise's strategic capability discussed above and the operational characteristics of power grid enterprise, we conclude the features of power supply enterprise's strategic capability as follow:

(1) Regionalism

As a kind of natural monopoly industry, the main business operation of power supply enterprise is to transfer, distribute, and sell electricity. Its operation is affected apparently by the region. The economic and social development of the city where the power supply enterprise locates determines its development rate and scale to a great degree.

(2) Comparability

In order to study the power supply enterprise's strategic capability, we can compare the present strategic capability with the former strategic capability or make comparison in the same industry, find out the gap, explore the reasons for the increase of decrease of strategic capability, and make progresses from one aspect or several aspects. On the other hand, we can compare the power supply enterprise with others in the same industry, position the power supply enterprise and make it learn from the excellent enterprises in the industry.

(3) Dynamic character

The dynamic character of power supply enterprise's strategic capability means the strategic capability changes along with the changes of market structure and competition behaviours, and the changes of enterprise's organizational structure. In other words, the advantages or disadvantages of the enterprise are not eternal. 


\section{(4) Integrity}

The strategic capability is the product of enterprise resource allocation as well as the product of integrating enterprise's business system and management system. The lack of any necessary resource or the imperfect integration of certain ring in systems will affect the cultivation and construction of strategic capability.

(5) Process character

The cultivation, construction, development, and declination of power supply enterprise's strategic capability need a process. As the power supply enterprise carries out its strategy, what the strategic capability focuses on is different at different stages. Therefore, the power supply enterprise should completely realize which stage it reaches in the life cycle and chiefly cultivate the capability that affects the whole strategic capability greatly.

\section{The construction of power supply enterprise's strategic capability}

The study of strategic capability aims at realizing the enterprise's sustainable growth and development by constantly improving its strategic values. The decomposition of strategic capability is to make the study of strategic capability more practical and operational. To decompose the abstract and implicit strategic capability into quantitative indexes and operational factors is to help the enterprise analyze, evaluate, and supervise its strategic capability and the changes on one hand. On the other hand, it is to compare the enterprise's strategic capability with others', providing with operational ways and methods for the enterprise cultivating, improving, and perfecting its strategic capability (Bin Yang \& Changtie Zhao, 2007, p152-156).

Therefore, according to the viewpoints of the capability school and the resource school, we design the "five-force" mode for the construction of enterprise's strategic capability from the angle of production and operation process, based on the power supply enterprise's business management needs. The "five- force" of the enterprise includes the decision capability, the execution capability, the innovation capability, the culture capability, and the operation capability. The enterprise decision is the start of all business activities. The decision can generate definite business means, collecting strengths by the lead process, and regulating behaviours by the management process. All will be embodied in the execution. Whether the enterprise decision can be executed effectively or not is determined by the decision capability. Corporate culture is the sum of values, creeds, and behavioural regulations shared in the enterprise. Corporate culture is the soul of an enterprise. It is the top guiding rule for employees' behaviours. By influencing employees' behaviours and thoughts, it can affect the enterprise's decision, innovation, and execution. Innovation is the source of enterprise's sustainable development and the motive of enterprise's all sources and capabilities exerting their effects. Innovation can effectively drive the improvement of enterprise's all capabilities. Therefore, innovation is the core of strategic capability. The enterprise's decision, execution, innovation, and culture determine its operation performance. In the continuous production and operation process, the operation performance can affect the enterprise's decision, execution, innovation, and culture conversely. The specific structure is displayed in the figure 1.

\section{The power supply enterprise's strategic capability evaluation model}

\subsection{The selection of evaluation indexes}

In order to get the exact and effective evaluation results, the selection of evaluation indexes should follow the principle of being systematic, comprehensive, rational, and effective. We evaluate the power supply enterprise's strategic capability from five aspects, namely the decision capability, the execution capability, the innovation capability, the culture capability, and the operation capability. In addition, we divide these five forces further and construct a multi-factor index system for the strategic capability evaluation (see table 1).

\subsection{The establishment of index weight}

According to the characteristics of the index system for the enterprise's strategic capability evaluation, in order to make every index weight in accord with objective practice, this paper adopts the analytic hierarchy process (AHP) to establish the index weight.

The author takes the calculation of the weights of management structure, decision mechanism, and risk management ability versus that of decision capability as example, using the AHP to establish the weights of indexes.

(1) Establish the judgement matrix according to the importance of management structure, decision mechanism, and risk management ability to decision capability.

(2) Calculate the multiplication of each line in the matrix ${ }^{M_{i}}$, make the n evolution of $M_{i}$ and get the $\mathrm{n} \operatorname{root}^{\overline{W_{i}}}$.

$$
\begin{aligned}
& \sqrt[3]{1 * 1 * 5}=\sqrt[3]{5}=1.71 \\
& \sqrt[3]{1 * 1 * 5}=\sqrt[3]{5}=1.71 \\
& \sqrt[3]{1 / 5 * 1 / 5 * 1}=\sqrt[3]{1 / 25}=0.34
\end{aligned}
$$


(3) Normalize the vector $\bar{W}_{i}$ and get the eigenvector ${ }^{W_{i}}$, namely the index weight.

$\left[\begin{array}{l}\frac{1.71}{1.71+1.71+0.34} \\ \frac{1.71}{1.71+1.71+0.34} \\ \frac{0.34}{1.71+1.71+0.34}\end{array}\right]=\left[\begin{array}{lll}0.45 & 0.45 & 0.10\end{array}\right]$

(4) Test the consistency of the judgement matrix and calculate the maximum latent root $\lambda_{\max }$.

$\lambda_{\max }=\sum_{i=1}^{n} \frac{(A W)_{i}}{n W_{i}}=3$

(5) Calculate the consistency index CI.

$\mathrm{CI}=\left(\lambda_{\max }-\mathrm{n}\right) /(\mathrm{n}-1)$

$=(3-3) /(3-1)=0$

(6) The random consistency rate $\mathrm{CR}$.

$\mathrm{CR}=\mathrm{CR} / \mathrm{RI}=0 / 0.58=0$

Due to $C R=0<0.1$, the judgement matrix has satisfying consistency. Therefore, the weights of management structure, decision mechanism, and risk management ability versus that of decision capability are respectively $0.45,0.45$, and 0.10 .

For other indexes' weights, the calculation methods and the consistency tests of judgement matrixes are similar. Here we do not provide with specific calculation processes. The specific indexes' judgement matrixes and weights are displayed as follow.

(1) Relevant weights of sub-indexes of decision capability

$\mathrm{U}_{1}=\left[\begin{array}{lll}\mathrm{U}_{11} & \mathrm{U}_{12} & \mathrm{U}_{13}\end{array}\right]=\left[\begin{array}{lll}0.45 & 0.45 & 0.10\end{array}\right]$

(2) Relevant weights of sub-indexes of execution capability

$\mathrm{U}_{2}=\left[\begin{array}{llllll}\mathrm{U}_{21} & \mathrm{U}_{22} & \mathrm{U}_{23} & \mathrm{U}_{24} & \mathrm{U}_{25} & \mathrm{U}_{26}\end{array}\right]=\left[\begin{array}{lllll}0.13 & 0.19 & 0.09 & 0.06 & 0.25\end{array}\right]$

(3) Relevant weights of sub-indexes of culture capability

$\mathrm{U}_{3}=\left[\begin{array}{llll}\mathrm{U}_{31} & \mathrm{U}_{32} & \mathrm{U}_{33} & \mathrm{U}_{34}\end{array}\right]=\left[\begin{array}{llll}0.11 & 0.32 & 0.26 & 0.31\end{array}\right]$

(4) Relevant weights of sub-indexes of innovation capability

$\mathrm{U}_{4}=\left[\begin{array}{llll}\mathrm{U}_{41} & \mathrm{U}_{42} & \mathrm{U}_{43} & \mathrm{U}_{44}\end{array}\right]=\left[\begin{array}{llll}0.23 & 0.14 & 0.36 & 0.27\end{array}\right]$

(5) Relevant weights of sub-indexes of operation capability

$\mathrm{U}_{5}=\left[\begin{array}{llllll}\mathrm{U}_{51} & \mathrm{U}_{52} & \mathrm{U}_{53} & \mathrm{U}_{54} & \mathrm{U}_{55} & \mathrm{U}_{56}\end{array}\right]=\left[\begin{array}{llllll}0.13 & 0.27 & 0.13 & 0.28 & 0.10 & 0.09\end{array}\right]$

(6) Relevant weights of levels of principle to strategic capability

$\mathrm{U}=\left[\begin{array}{lllll}\mathrm{U}_{1} & \mathrm{U}_{2} & \mathrm{U}_{3} & \mathrm{U}_{4} & \mathrm{U}_{5}\end{array}\right]=\left[\begin{array}{lllll}0.35 & 0.19 & 0.11 & 0.23 & 0.12\end{array}\right]$

\section{The empirical analysis}

We take a power supply enterprise in western China as an example and evaluate its strategic capability.

In order to make the score of every index reflect the enterprise's condition scientifically, rationally, and actually, we adopt different evaluation method for different evaluation index. This paper mainly uses three methods as follow in scoring the evaluation indexes.

(1) Expert evaluation method. For indexes that can not be graded quantitatively, a common way is to adopt the expert subjective evaluation method in making an integrated evaluation. In order to guarantee the expert evaluation results' objectiveness and consistency, we can systematically collect indexes' historical information and supply them for experts, and adopt the Delphi method to make evaluation, till finally get the consistent evaluation results.

(2) Management diagnostic questionnaire. In order to further understand the power supply enterprise's business management situation, we make up the management diagnostic questionnaire, by questions in which we can analyze and establish the sub-indexes.

(3) Grade the financial indexes. For indexes that can be evaluated objectively and quantitatively, such as the enterprise's business performance, we can collect data of yearly business plan and performance from the electric power bureau and 
make evaluation by comparison. Here we design the power supply enterprise's business performance evaluation method by taking reference from the State-owned Assets Supervision and Administration Commission of the State Council in evaluating the president's business performance in state-owned enterprise.

By these method discussed above, we can get the scores of the power supply enterprise's evaluation sub-indexes. Then, we can get the score of the power supply enterprise's strategic capability. The specific scores are displayed in table 3 .

Based on the evaluation and analysis, we find that this power supply enterprise possesses a relatively stronger integrated strategic capability. The enterprise's decision capability, culture capability, and operation capability are scored relatively high. The high decision capability can guarantee the enterprise's development direction. The better operation capability serves as the base of enterprise's future development. However, the enterprise's execution capability and innovation capability are scored relatively low. The poor execution capability leads to the enterprise's low work efficiency. The enterprise strategy and the managers' orders can not be carried out timely and effectively. The lack of innovation capability may fail the enterprise in sustainable development.

\section{Conclusion}

The strategic capability should not only guarantee the enterprise's survival and development in a short period, but also include the enterprise's optimal resource allocation capability in the long run. The strategic capability supports the enterprise to realize the continuous development, providing the enterprise with motives of sustainable development. Once an enterprise has the strategic capability, does the enterprise possess long-term competitive advantages, driving the enterprise develop fast. Only when an enterprise possesses better strategic capability, can it realize the sustainable development.

By decomposing and evaluating the enterprise's strategic capability, the decision-makers can evaluate the enterprise's strategic capability quantitatively, predict and master the enterprise's development more rationally, adjust and perfect the enterprise's development strategy, reducing the uncertain factors in the enterprise's development process, and finally making the enterprise enhance its competence and create better business performance in a steady development.

\section{References}

Guo, Yajun. (2007). Comprehensive Evaluation Theory, Method, and Application. Beijing: Science Press.

$\mathrm{Xu}$, Xiaoping. \& Liu, Wei. (2006). The systematic analysis and evaluation of corporate strategic capability. Journal of Harbin University of Commerce: Social Science Edition. No.6.

Yang, Bin. \& Zhao, Changtie. (2007). Research on multi-dimension construction of strategy capability. Science of Science and Management of S.\&.T. No.7. p152-156.

Zhang, Wensong. (2005). Corporate Strategic Capability. Beijing: Science Press. 
Table 1. The index system for the power supply enterprise's strategic evaluation.

\begin{tabular}{|c|c|c|}
\hline Level of objective & Level of principle & Specific sub-index \\
\hline \multirow{23}{*}{$\begin{array}{l}\text { Enterprise's } \\
\text { strategic capability } \\
\text { U }\end{array}$} & \multirow{3}{*}{$\begin{array}{l}\text { Decision capability } \\
\mathrm{U}_{1}\end{array}$} & Management structure $\mathrm{U}_{11}$ \\
\hline & & Decision mechanism $U_{12}$ \\
\hline & & Risk management ability $\mathrm{U}_{13}$ \\
\hline & \multirow{6}{*}{$\begin{array}{l}\text { Execution capability } \\
\mathrm{U}_{2}\end{array}$} & Approval degree of strategy $\mathrm{U}_{21}$ \\
\hline & & Organizational frame $U_{22}$ \\
\hline & & System $\mathrm{U}_{23}$ \\
\hline & & Operational process $\mathrm{U}_{24}$ \\
\hline & & Plan-target management $\mathrm{U}_{25}$ \\
\hline & & Execution culture $\mathrm{U}_{26}$ \\
\hline & \multirow{4}{*}{$\begin{array}{l}\text { Culture capability } \\
\mathrm{U}_{3}\end{array}$} & Enterprise image $\mathrm{U}_{31}$ \\
\hline & & Internal harmony $\mathrm{U}_{32}$ \\
\hline & & Construction of corporate culture $\mathrm{U}_{33}$ \\
\hline & & Enterprise cohesion $\mathrm{U}_{34}$ \\
\hline & \multirow{4}{*}{$\begin{array}{l}\text { Innovation capability } \\
\mathrm{U}_{4}\end{array}$} & Personnel structure $\mathrm{U}_{41}$ \\
\hline & & Enterprise's innovation environment $\mathrm{U}_{42}$ \\
\hline & & Learning ability $\mathrm{U}_{43}$ \\
\hline & & Input and output of innovation $U_{44}$ \\
\hline & \multirow{6}{*}{$\begin{array}{l}\text { Operation capability } \\
U_{5}\end{array}$} & Operation resource $U_{51}$ \\
\hline & & Strength of power grid $U_{52}$ \\
\hline & & Customer service $\mathrm{U}_{53}$ \\
\hline & & Safety management $\mathrm{U}_{54}$ \\
\hline & & Operation performance $\mathrm{U}_{55}$ \\
\hline & & Organization response degree $\mathrm{U}_{56}$ \\
\hline
\end{tabular}

Table 2. The judgement matrix of decision capability's sub-indexes.

\begin{tabular}{l|lll}
\hline $\mathrm{U}_{1}$ & $\mathrm{U}_{11}$ & $\mathrm{U}_{12}$ & $\mathrm{U}_{13}$ \\
\hline $\mathrm{U}_{11}$ & 1 & 1 & 5 \\
$\mathrm{U}_{12}$ & 1 & 1 & 5 \\
$\mathrm{U}_{13}$ & $1 / 5$ & $1 / 5$ & 1 \\
\hline
\end{tabular}


Table 3. The strategic evaluation scores of the power supply enterprise in western China.

\begin{tabular}{|c|c|c|c|}
\hline & Evaluation index & Score & $\begin{array}{l}\text { Strategic } \\
\text { capability score }\end{array}$ \\
\hline \multirow{5}{*}{$\begin{array}{l}\text { Strategic } \\
\text { capability }\end{array}$} & Decision capability & 80.8 & \multirow{5}{*}{80.6} \\
\hline & Execution capability & 77.1 & \\
\hline & Culture capability & 82.6 & \\
\hline & $\begin{array}{l}\text { Innovation } \\
\text { capability }\end{array}$ & 77.2 & \\
\hline & Operation capability & 86.9 & \\
\hline
\end{tabular}

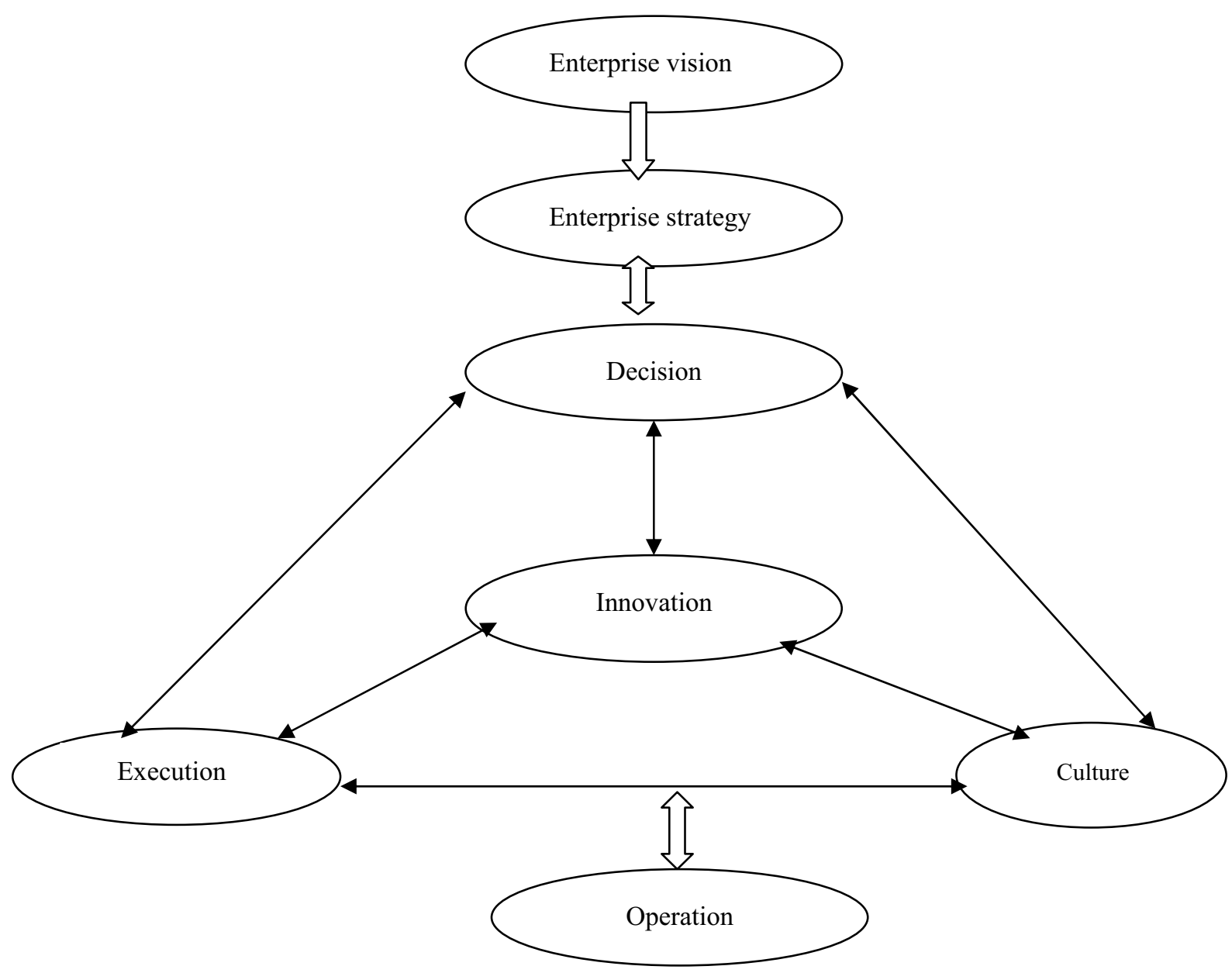

Figure 1. The Power Supply Enterprise's Strategic Capability Structure Model. 